\title{
Spatial and Temporal Analysis of Groundwater Recharge with Application to Sampling Design Igor Jankovic ${ }^{1}$, Roko Andricevic ${ }^{2}$, Efi Foufoula-Georgiou ${ }^{1}$
}

Technical Report Number 140 Water Resources Research Center

University of Minnesota

St. Paul, Minnesota

July, 1995

\footnotetext{
'Department of Civil Engineering, University of Minnesota, Minneapolis

${ }^{2}$ Desert Research Institute, University System of Nevada, Water Resources Center, Las Vegas, Nevada
} 
This constitutes the final report for a WRRC project directed by Igor Jankovic, Efi Foufoula-Georgiou, University of Minnesota, and Roko Andricevic, Desert Research Institute, University System of Nevada, Water Resources Center, Las Vegas, Nevada, entitled: Spatial and Temporal Analysis of Groundwater Recharge with Application to Sampling Design. This project was funded for the period July 1991 to June 1993.

The work upon which this publication is based was supported in part by funds provided by the U. S. Department of the Interior, U.S. Geological Survey, and the Water Resources Research Center, University of Minnesota as authorized by the Water Resources Research and Development Act of 1984.

Contents of this publication do not necessarily reflect the views and policies of the U.S. Department of the Interior, nor does mention of trade names of commercial products constitute their endorsement by the U.S. Government.

The University of Minnesota is an equal opportunity employer and educator.

\author{
Water Resources Research Center \\ Patrick L. Brezonik, Director \\ 1518 Cleveland Avenue, North \\ University of Minnesota \\ St. Paul, MN 55108 \\ (612) 624-9282 \\ Fax (612) 625-1263
}




\section{Abstract}

The most influential process for the groundwater shallow aquifer monitoring is groundwater recharge. This study focuses on defining and quantifying the groundwater recharge as a process primarily resulting from precipitation. The spatial and temporal distribution of the recharge was analyzed through a numerical experiment designed to realistically describe a shallow aquifer case. The spatial and temporal structure of the recharge was examined and quantified as a function of precipitation events and soil heterogeneity. The quantified spatial and temporal distribution of the groundwater recharge then was used to demonstrate its influence on sampling network design. It was found that the temporal variability of the recharge has a major impact on the design of groundwater flow monitoring networks. 


\section{Table of Contents}

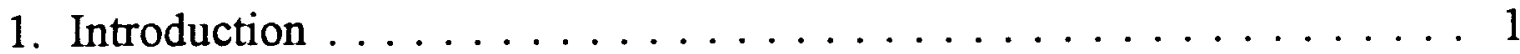

2. Recharge Definition $\ldots \ldots \ldots \ldots \ldots \ldots \ldots$

3. Description of Numerical Experiment $\ldots \ldots \ldots \ldots$

4. Saturation Profiles and Lateral Flow $\ldots \ldots \ldots \ldots \ldots$

5. Recharge Spatial Structure $\ldots \ldots \ldots \ldots \ldots \ldots \ldots$

6. Recharge Temporal Analysis . . . . . . . . . . . . 24

7. Spatial and Temporal Sampling Design for Unsteady Groundwater

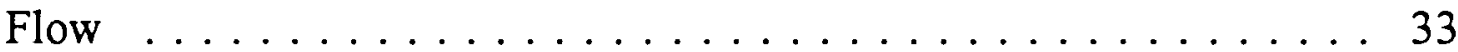

8. Concluding Remarks . . . . . . . . . . . . . 36

References $\ldots \ldots \ldots \ldots \ldots \ldots \ldots \ldots \ldots \ldots$ 


\section{Introduction}

The natural recharge of groundwater is of fundamental importance for groundwater exploration and economic development studies. In groundwater recharge studies the two most important issues are: (1) definition and identification of groundwater recharge mechanisms for specific areas and (2) determination of the spatial and temporal variability of groundwater recharge.

A common assumption in dealing with groundwater recharge, particularly in the case of modeling the saturated zone, is its local spatial uniformity (Besbes and de Marsily, 1984) and temporal linearity (Morel-Seytoux, 1984). However, many field studies (Allison, 1988; Johnston, 1987; Sharma and Hughes, 1985) revealed the possible strong (an order of magnitude) recharge variability in space and time. Sharma and Huges (1985) reported that about $50 \%$ of the groundwater recharge in Western Australia occurs through the so-called preferred pathways and consequently exhibits large spatial variability. Johnston (1987) found through recharge measurements that the groundwater recharge varies over scales of a few meters in many soil types. Whatever the reason for that spatial and temporal variability is, its presence is important for groundwater resources management studies and should not be ignored.

One of the difficulties in studying groundwater recharge is that it has a different meaning for different people. For example, an agronomist would consider the movement of water beneath the root zone as a loss in yield, while those interested in water resources would take the opposite view. This yields to different definitions as well as different techniques for estimating recharge. Commonly, groundwater recharge is estimated with chemical, isotopic, and physical methods (using measurements or numerical modeling) depending on the climate conditions of the area and depth to the water table. Solomon and Sudicky (1991) attempted to use the combined measurements of tritium and helium-3 isotope to estimate groundwater recharge by defining the groundwater velocity near the water table. A review of some chemical and isotopic techniques for estimating groundwater recharge can be found in Allison (1988).

This study is concerned with quantification of the spatial and temporal variability of groundwater recharge as a function of rainfall and porous medium properties. The spatio-temporal changes of this natural process possesses a certain structure at the macroscopic level and purely random character at the microscopic level. This macroscopic variability plays an important role in understanding, modeling, and predicting the aquifer responses, and neglecting such spatio-temporal variability in water management models, for example, may adversely influence management decisions.

The original objective of the presented study was to evaluate sampling network design for groundwater quality monitoring using data from a well studied and 
highly sampled landfill in Anoka, Minnesota (the Anoka landfill). Groundwater monitoring well-network design for this field was previously investigated by Quinn et al. (1994) who followed an approach based on a deterministic flow model of the saturated zone. Discrepancies between their numerical results and experimental findings indicated the importance of unsaturated zone and soil heterogeneities in quantification of pollutant transport. Our approach has addressed heterogeneities in a stochastic manner and has also included flow in the unsaturated zone. During the data assimilation stage of the project, we found that the data available for the Anoka landfill (i.e. hydraulic head and hydraulic conductivity) were not sufficient for the purposes of our analysis. This prompted our research to focus more on the actual processes that contribute most to the sampling performance of a monitoring network designed in space and time rather than the specific application to Anoka landfill.

Our study employed a numerical modeling approach to quantify the macroscopic structure of the groundwater recharge variability. Flow in heterogeneous, variably saturated, porous media has been extensively investigated. Both measurements (Hills et al., 1991; Johnston, 1987; Sharma and Hughes, 1985) and numerical models of flow through the unsaturated zone (Polmann et al., 1991; Protopapas and Bras, 1991) indicate the existence of lateral flow patterns and consequently their strong spatial variability. In this study we concentrate on the groundwater recharge that results from the percolation of excess rainfall, and we quantify its spatial and temporal structure as a function of the input precipitation process and heterogeneity of the hydraulic conductivity field. 


\section{Recharge Definition}

Groundwater recharge is commonly described as the quantity of water that crosses the phreatic surface and becomes part of the groundwater system (Anderson and Woessner, 1992). At a daily scale this process starts with the daily rainfall, which after filling interception and depression storage partially becomes surface runoff and partially infiltrates in the upper soil zone. The daily rainfall excess minus daily evapotranspiration losses replenish the upper soil zone. Then, the moisture excess with respect to the soil capacity percolates downward to finally replenish the groundwater table and constitutes the groundwater recharge. However, to study the spatio-temporal variability of the groundwater recharge process it is necessary to define it mathematically in a precise way.

The continuity of the water flux and pressure across the phreatic surface is a necessary and sufficient boundary condition that enables one to use separate models for unsaturated and saturated zones. However, only the water flux across the moving phreatic surface toward the saturated zone should be considered as recharge. For the specific case when water enters the phreatic surface, the corresponding rate, $J$, can be expressed in the form (Bear, 1991):

$$
J=N+\epsilon u
$$

where $N$ is the advective flux vector normal to the phreatic surface (positive toward the saturated zone), $\epsilon$ is the effective porosity, $u$ is the velocity of the phreatic surface in the normal direction (positive toward the unsaturated zone). The advective flux $N$ describes the combined effects of possible accretion from the unsaturated zone towards the phreatic surface and flux caused by the groundwater flow conditions in the saturated zone (e.g., resulting from the continuity of total mass flux at the phreatic surface). This advective flux, which represents the rate at which the water is added to or removed from the saturated zone, does not describe actual recharge unless corrected by the movement of the phreatic surface. In other words, the advective flux $N$ is expressed in fixed (Eulerian) coordinates and does not represent the actual amount of water that augments or reduces the quantity of water in the saturated zone. This amount of water is what we define here as recharge. The advective flux $N$ is obtained on the macroscale using Darcy's law. The second term in (1) reflects the movement of the phreatic surface and is necessary in order to have recharge defined as the total flux relative to the phreatic surface velocity. This term is obtained as a change in storage resulting from the phreatic surface movement. Thus, we can now define the recharge in the material (Lagrangian) coordinates $\xi_{i}, i=1,2,3$, or in the form of the initial position vector $\xi$ of a point at the phreatic surface at time zero (e.g., $\left.\xi \equiv \mathbf{x}\right|_{t=0}$ ). 


$$
R(\xi, t)=\frac{\partial h(\mathbf{x}, t)}{\partial n_{p}} k+\frac{\partial h(\mathbf{x}, t)}{\partial t} \epsilon
$$

where $h(\mathbf{x}, t)$ is the hydraulic head in fixed (Eulerian) coordinates, $n_{p}$ is a unit vector normal to the phreatic surface, and $k$ is the saturated hydraulic conductivity. Note that while a point on the phreatic surface moves, its position coordinates $(\mathbf{x})$ vary in time, whereas its material coordinates $\xi$, remain unchanged (e.g., $\mathbf{x}=\mathbf{x}(\xi, t)$ ).

By assuming a locally horizontal phreatic surface the actual recharge can be further simplified

$$
R(\xi, t)=\frac{\partial h(\mathbf{x}, t)}{\partial z} k+\frac{\partial h(\mathbf{x}, t)}{\partial t} \epsilon
$$

where $z$ is positive upwards.

This analysis provides the mathematical framework to quantify groundwater recharge on the phreatic surface as a combined effect of two terms; (1) the water flux across the phreatic surface which is independent of the location and (2) the velocity at which the phreatic surface moves. It is the combined influence of the above two terms that describes the rate at which the water actually augments, or reduces the quantity of water in the saturated zone. Thus, the groundwater recharge process has to be understood as a process located on the moving interface between unsaturated and saturated zone.

It is interesting to analyze some special cases when estimating the recharge in practice. The most common practical case is when the groundwater flow in the saturated zone is (or assumed to be) in steady condition (flow only in the unsaturated zone) during the time frame when the recharge is sought. Then, the first term in (3) disappears at the phreatic surface (due to the continuity of total mass flux at the phreatic surface) and recharge can be estimated by evaluating only the change in storage (second term in (3)). In other cases when the groundwater flow in saturated media is unsteady, both terms in (3) contribute to the groundwater recharge description. 


\section{Description of the Numerical Experiment}

Numerical simulation was used to evaluate the groundwater recharge for a shallow aquifer case. Daily groundwater recharge was simulated over a 90-day time-period. The domain of numerical simulation is shown in Figure 1 and all model input parameters are given in Table 1. The porous domain used in the numerical experiment was a vertical cross-section $(x, z)$ plane containing an unsaturated zone and a saturated zone. The boundaries of the domain were taken to be impervious, except at the soil surface. The impervious vertical boundary condition results in a vertical water flux, yielding horizontal equi-saturation lines. The influence from the boundary conditions on the numerical simulation can be measured by the slope of the equi-saturation lines. We found that the affected area was approximately $5 \%$ on each side, which is in agreement with the study by Rubin and Dagan (19S8), who quantified this influence to be approximately three correlation lengths of the hydraulic conductivity.

The saturated hydraulic conductivity was generated using the Turning Bands Algorithm (Tompson et al., 1987) as a spatially random field, block-heterogeneous and isotropic. All blocks were identical rectangles corresponding to quadrilateral finite elements that were used to solve the numerical model. The block hydraulicconductivity field varied smoothly from block to block, following a two-dimensional $(x, z$ plane) statistically anisotropic exponential autocovariance, as a function of the separation vector $\mathbf{r}=\left(r_{x}, r_{z}\right)$

$$
C_{k}(\mathbf{r})=\sigma_{k}^{2} \cdot \exp \left(-\left[\left(\frac{r_{x}}{\lambda_{x}}\right)^{2}+\left(\frac{r_{z}}{\lambda_{z}}\right)^{2}\right]^{\frac{1}{2}}\right)
$$

where $\sigma_{k}^{2}$ is the variance of the hydraulic conductivity and $\lambda_{x}$ and $\lambda_{z}$ are correlation lengths in the $x$ and $z$ direction, respectively. The horizontal correlation length was set to be approximately seven times larger than the vertical correlation length in order to simulate the horizontally layered medium.

The rain series used as input in the numerical simulation experiment was taken to be spatially uniform over the domain of simulation, and temporary uniform within a day. Actual precipitation data from the Minneapolis/St. Paul International Airport were used for the analysis. This site was selected because of its quality of rainfall records and proximity to the site of interest (Anoka landfill). For each year of the 30 years of record, the 3-month period of June, July, August was chosen and a spectral analysis of daily precipitation was performed. The results showed consistency of spectra over the years and within the 3 -month period itself. This indicated that this period exhibits an ergodic behavior and is therefore appropriate for our analysis (as the results would not be specific to a particular year but rather representative of the summer season in the vicinity of the Minneapolis/St. Paul International 


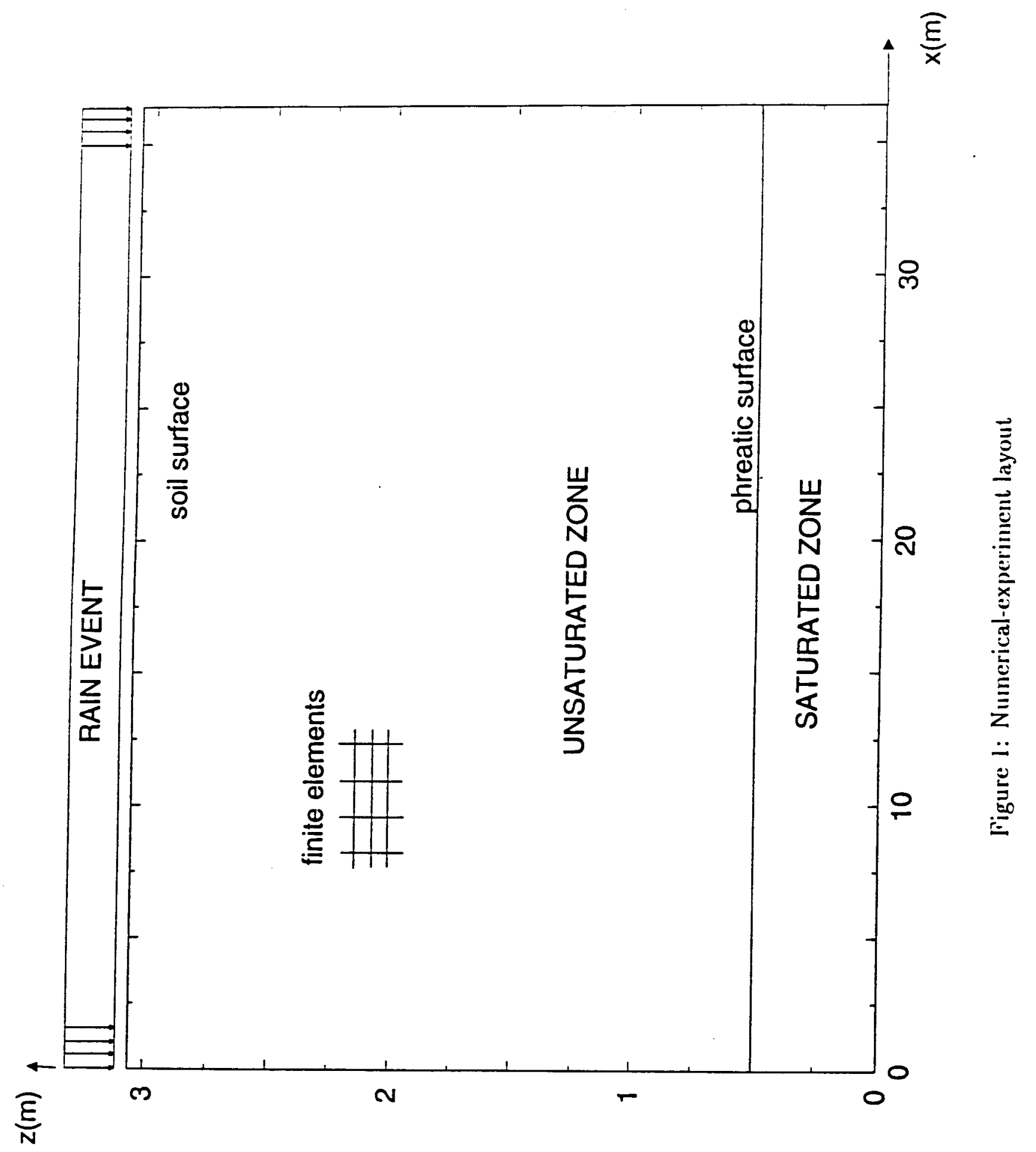




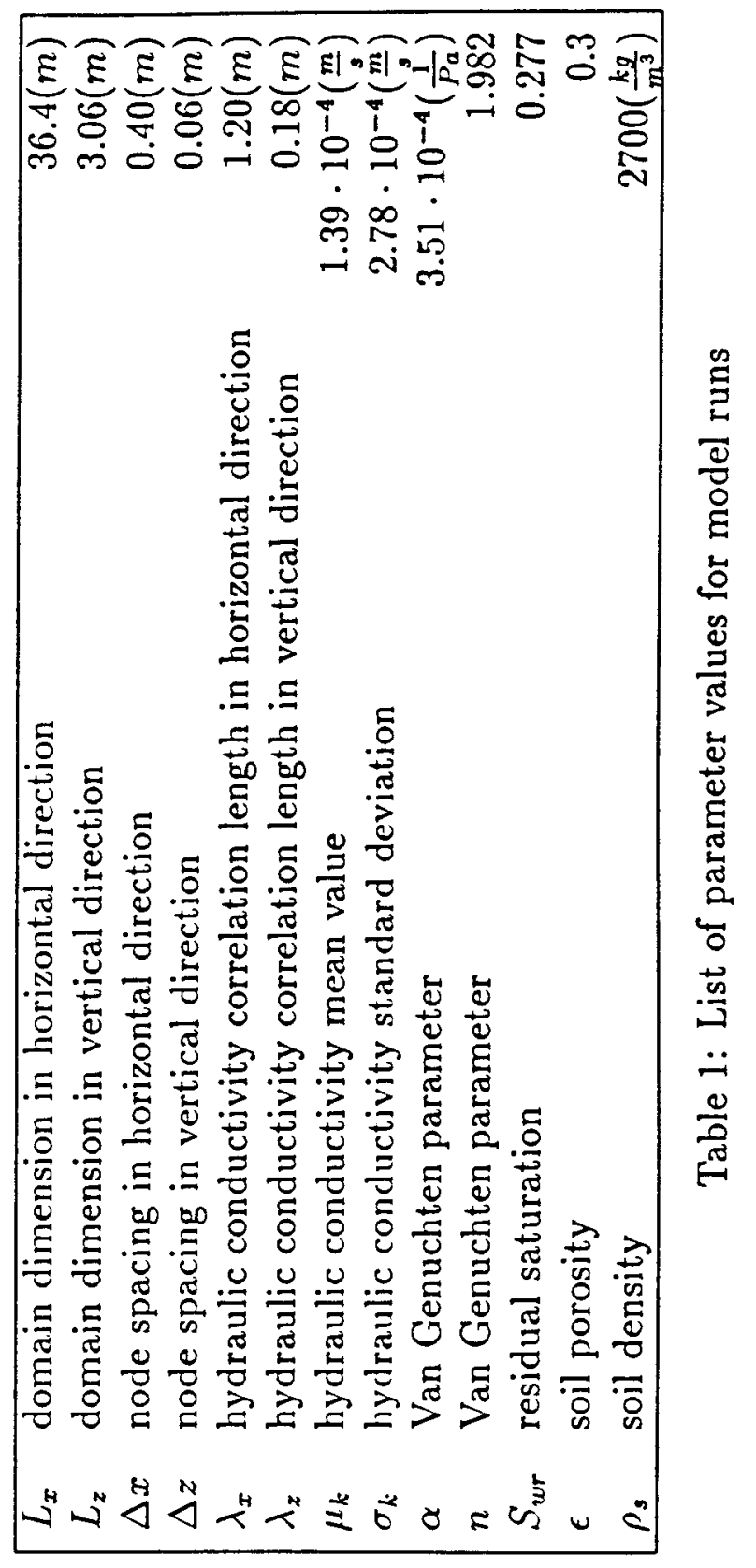


Airport). Three different rain series from years 1969, 1970, 1973 (e.g. Figure 2) and their transformation into recharge were used in this experiment. For each series, 10 different hydraulic conductivity realizations were generated to describe the soil saturated hydraulic conductivity field. For each rain series and each hydraulic conductivity realization, the numerical solution of flow equations in the variably saturated porous media was obtained.

The evapotranspiration process was assumed to be constant in time and uniform over the horizontal plane but vertically variable within $2(m)$ below the soil surface. The total volume of evapotranspiration was chosen to be one-third of the total volume of rain (in agreement with the Anoka field site-specific estimates of Quinn et al., 1994). The vertical distribution of evapotranspiration was described as a function of the distance, $r_{z}$, from the soil surface and the evapotranspiration intensity at the soil surface (e.g. Srebrenovic, 1986):

$$
e\left(r_{z}\right)= \begin{cases}e_{s} \frac{r_{z}^{2}}{2} & \text { for } r_{z} \leq 2 \\ 0 & \text { for } r_{z}>2\end{cases}
$$

where $e\left(r_{z}\right.$ ) is the evapotranspiration intensity (in $\mathrm{kg} \mathrm{m}^{-3} \mathrm{~s}^{-1}$ ) at distance $r_{z}$ from the soil surface and $e_{s}$ is the evapotranspiration intensity at the soil surface.

To obtain the ground water recharge at the phreatic surface, the numerical model (based on the domain in Figure 1) must solve Richard's equation expressed (in this study) in the pressure form:

$$
\frac{\partial\left(\epsilon S_{w} \rho_{w}\right)}{\partial t}=-\nabla \cdot\left(\epsilon S_{w} \rho_{w} v\right)-e(z)
$$

where $S_{w}$ is the saturation, $\rho_{w}$ is the water density, and $v$ is the water velocity obtained through Darcy's law. Darcy's law is expressed for variably saturated porous media as:

$$
S_{w} \epsilon v=q=-\frac{k k_{r}}{\rho_{w} g}\left(\nabla p+\rho_{w} g \nabla z\right)
$$

where $p$ is the water (pore) pressure, $k_{r}$ is the relative hydraulic conductivity, and $g$ is the gravitational acceleration. We employ the van Genuchten relations (van Genuchten, 1980) to relate the pore pressure $(p)$, saturation $\left(S_{w}\right)$ and the relative hydraulic conductivity $\left(k_{r}\right)$ in the unsaturated zone:

$$
\begin{gathered}
S_{w}=S_{w r}+\left(1-S_{w r}\right)\left[\frac{1}{1+\left(\alpha p_{c}\right)^{n}}\right]^{\frac{n-1}{n}} \\
k_{r}=\left(S_{w}^{*}\right)^{0.5}\left[1-\left(1-\left(S_{w}^{*}\right)^{\frac{n}{n-1}}\right)^{\frac{n-1}{n}}\right]^{2}, \quad S_{w}^{*}=\frac{S_{w}-S_{w r}}{1-S_{w r}}
\end{gathered}
$$

where $\alpha$ and $n$ are model parameters, $S_{w r}$ is the residual saturation, and $p_{c}$ is the capillary pressure. All model parameters were treated as constant in space. 


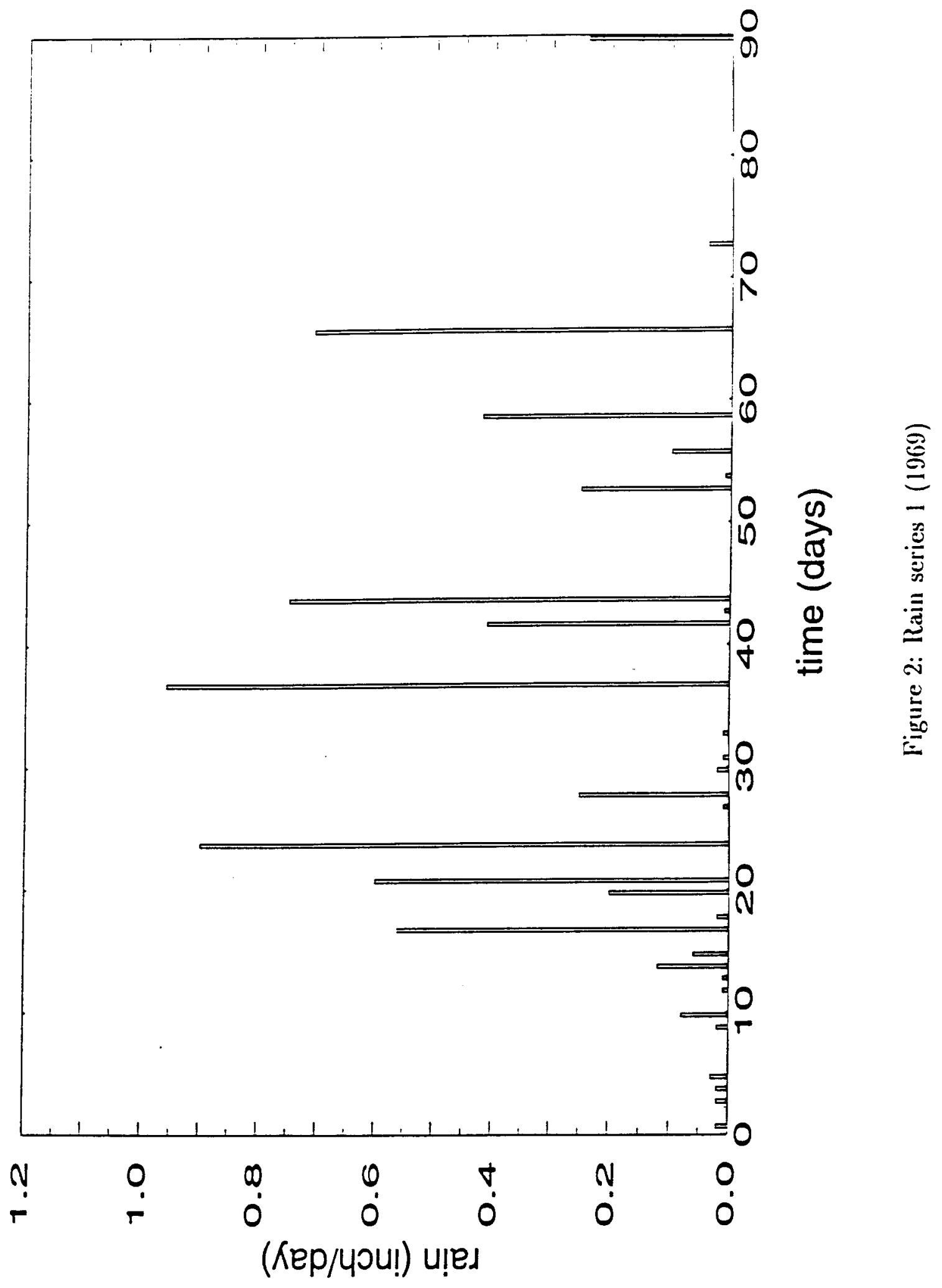


The initial condition for the pore pressure field was chosen on the basis of the hydrostatic pressure distribution with the phreatic surface $0.5(m)$ above the domain bottom (Figure 1). The corresponding saturation values then were obtained using equation (8). The soil surface is the boundary of a given vertical flux, equal to precipitation $P_{t}$, if the infiltration capacity of the soil is not exceeded:

$$
P_{t}=\frac{k k_{r}}{\rho_{w} g}\left(\frac{\partial p}{\partial z}+\rho_{w} g\right)
$$

If the infiltration capacity of the soil is exceeded, the numerical model solution returns a non-negative pressure value at the soil surface indicating saturated soil surface - ponding. In that case, the boundary condition in equation (10) must be changed to reflect the actual pressure of the water ponded on the soil surface. In our experiment we did not consider the effect of the ponded water, and therefore we set $p=0$.

The numerical solution of the above governing equations utilized finite elements for spatial discretization and a fully implicit method for temporal integration of equation (6). The execution speed and the solution accuracy have conflicting requirements regarding the selection of the time step. Namely, larger time steps are needed for faster execution, but smaller time steps provide a better solution accuracy. In addition, large time steps tend to smear the solution, particularly in the case of an implicit temporal integration scheme and can also cause divergence. On the other hand, small time steps are needed to capture the rapid changes of soil saturation in the zone just below the soil surface, caused by sudden changes of the rain intensity. The problem of selecting the appropriate time step is commonly bypassed by employing an adjustable time step (Kirkland et al., 1992). The time step is increased if the changes in the subsurface system are slow, and decreased if the changes are fast. In this study we started the simulation with a basic time step of 2 hours and reduced it if the convergence was not achieved after a certain number of iterations.

After the numerical model is solved, the groundwater recharge is calculated using equation (3). The time step used in evaluation of the second term of equation (3) was set to one day. 


\section{Saturation Profiles and Lateral Flow}

The numerical model solution was used to analyze the spatial structure of groundwater recharge. Thirty different model solutions (10 realizations of the hydraulic conductivity field for three rain series) were obtained and used for the groundwater recharge analysis. The results show that the direction of flow is depth-dependent. In the soil zone close to the phreatic surface, the horizontal component of the flow is negligible, but it is significant near the soil surface. The horizontal component of the water flow, which can be seen from saturation profiles in Figure 3, is primarily caused by the heterogeneity of the hydraulic conductivity field. The lateral flow is particularly intensified during strong rain events, and it diminishes for the lower-intensity rain events. In addition, the closer the phreatic surface is to the soil surface, the less intensive is the lateral flow; the recharge spatial structure approaches the rain spatial structure asymptotically. The existence of flow patterns that lead to lateral flow in dry soil zones has been observed in field studies (Allison, 1988; Hills et al., 1991; Johnston, 1987; Sharma nad Hughes, 1985), as well as in numerical experiments (Polmann et al., 1991).

The heterogeneity of the hydraulic conductivity field in the soil zone close to the phreatic surface has little or no impact on the development of groundwater recharge and its spatial structure, since the lateral flow is not significant in this zone. In this soil zone saturation is influenced by changes in the phreatic surface elevation, such that the saturation profiles are translated by an amount equal to the phreatic surface elevation change. An example of this behavior can be seen in Figure 3 where the three days used to illustrate the conditions before the peak (day 44), during the peak (day 46) and after the peak (day 53).

The above discussion indicates the possibility of dividing the unsaturated zone in two portions with respect to flow direction. The upper portion of the unsaturated zone acts as a reservoir (small time lag) where moisture deficit may exist with respect to the soil capacity (because of evapotranspiration). The remaining portion down to the phreatic surface acts as a linear reservoir (large time lag), resulting in translation of the saturation profiles by the amount that the phreatic surface elevation changes.

Because the lateral flow in the upper soil zone is related to the hydraulic conductivity field and to the degree of saturation, it may be possible to use that relationship to infer the soil heterogeneity structure in the top-soil zone. Figure 4 shows the relationship between the vertically averaged saturated hydraulic conductivity $(1(\mathrm{~m})$ of the top-soil layer) and the corresponding averaged saturation value for the horizontal domain of Figure 1 and for day 48 of rain series 1 . The higher conductivity zones are less saturated because they are draining faster, and the lower hydraulic conductivity zones correspond to larger saturation. The results seem to indicate an exponential relation between the saturated hydraulic conductivity and the saturation. This was found to be the case for other infiltration stages and all hydraulic 


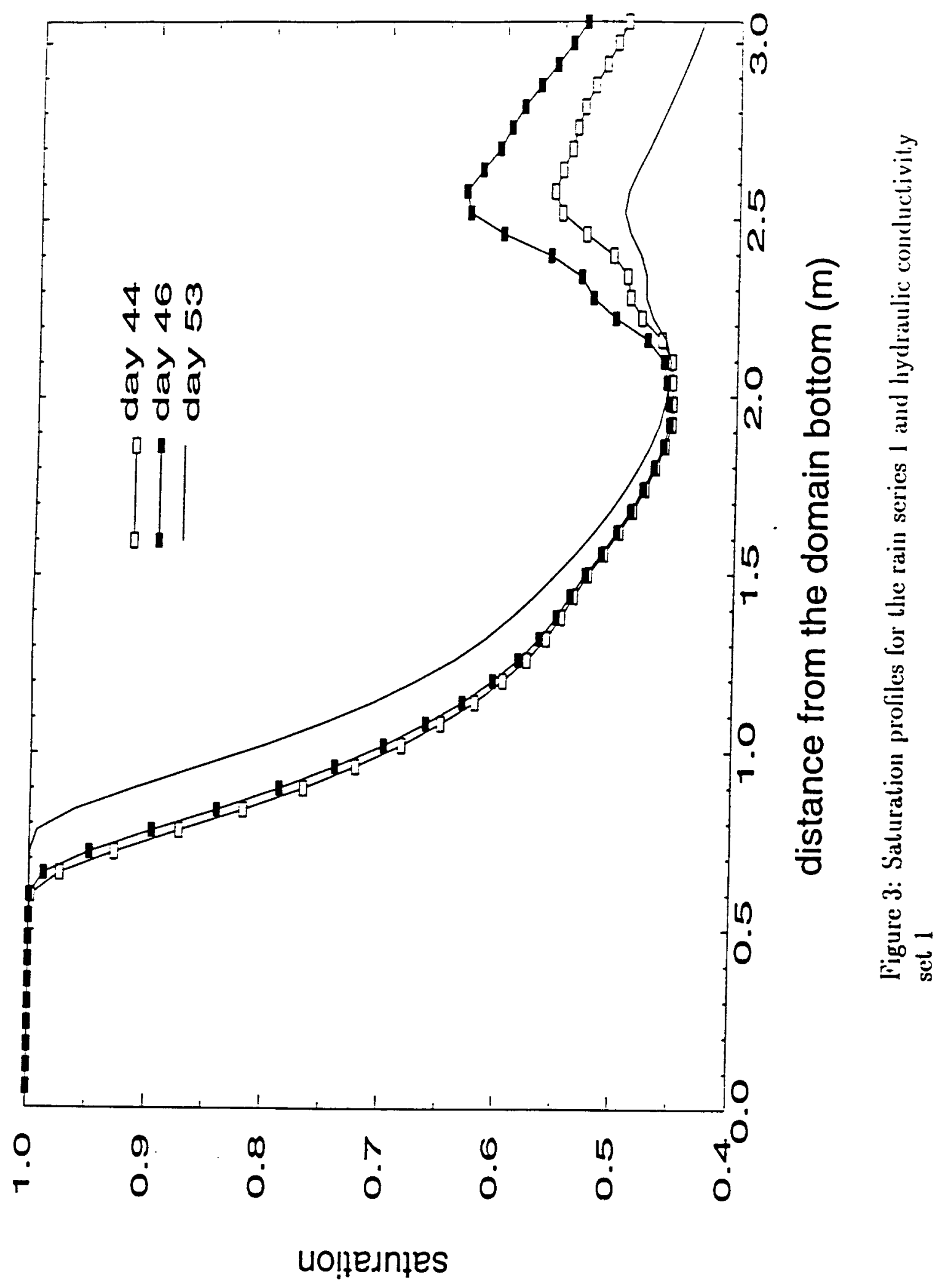




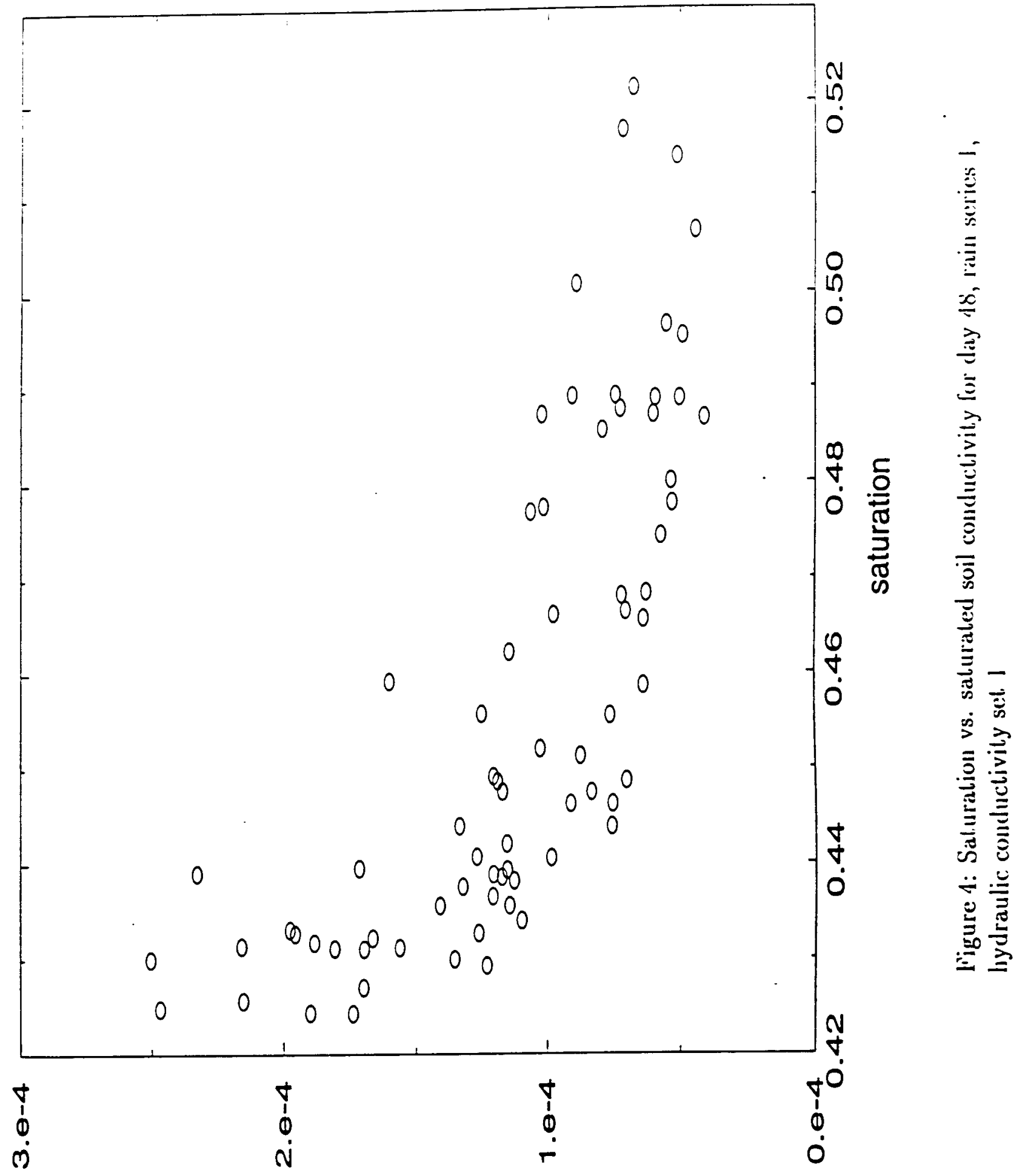

(s/m) K!!!!ฺnpuoo l!os pəłednłes 
conductivity realizations; the only difference was that the range of saturation values depended on rainfall intensity and infiltration travel times. An interesting conclusion is that it might be possible to quantify the heterogeneity structure of the top-soil hydraulic conductivity by measuring the saturation as a surrogate information for hydraulic conductivity. For example, using the Time Domain Reflectometry (TDR) technique (Topp et. al., 1980) to measure the soil water content in the top-soil zone may provide valuable information, which together with hydraulic conductivity data may indicate the relationship between hydraulic conductivity and saturation. As a result, one may generate the hydraulic conductivity field conditioned on both saturation and hydraulic conductivity data. TDR provides an inexpensive and fairly accurate way of measuring the soil water content and may be used to infer the saturated hydraulic conductivity for the top-soil zone. This may help to better understand the potential for migration of pollutants towards the saturated zone. 


\section{Recharge Spatial Structure}

The first recharge that occurs at the phreatic surface level is the water percolating through preferential flow paths of high hydraulic conductivity. This can be seen on the recharge spatial distribution for day 47 (day of peak recharge) and rain series 1 (from 1969) in Figure 5. The preferential pathways are very active in the rising limb of the recharge peak and they dry out quickly after the peak, when the groundwater continues to be recharged from other less conductive soil zones (e.g., Figure 6 - day 49). Although recharge from particular days (e.g. day 47 and day 49 on Figure 5 and 6) exhibits a strong spatial non-uniformity, when averaged over larger time scales (e.g. average between day 47 and day 49 in Figure 5 and 6), it shows more uniform behavior in space.

The recharge correlation length is adopted as a quantitative measure of the spatial nonuniformity of the groundwater recharge. Asymptotically, a uniform process yields an infinite correlation distance; a finite correlation distance identifies a degree of non-uniformity. For this analysis, time is considered as a parameter such that the recharge spatial correlation scale is compared at different time instances corresponding to different stages of the recharge process. The correlation length of a spatial process is described as an integral scale. In the experiment performed with an horizontal phreatic surface, the recharge integral scale is defined as:

$$
\lambda_{R}=\frac{1}{\sigma_{R}^{2}} \int_{0}^{\infty} C_{R}(\mathbf{r}) d \mathbf{r},
$$

where $\sigma_{R}^{2}$ is the groundwater recharge variance and $C_{R}(\mathbf{r})$ is the groundwater recharge covariance function with $\mathbf{r}$ a separation vector (in our case this represents separation in horizontal direction only).

Figure 7 shows the evolution of the recharge correlation scale plotted as a function of different time instances around the recharge peak for the rain series 1 (Figure 2 ). The small correlation on day 47 indicates the presence of preferential pathways. On day 48 , recharge occurs through both preferential pathways and other soil zones, yielding an increase in the correlation scale. Preferential pathways dry out faster than other soil zones, and the correlation decreases again (day 49). After the peak, recharge exhibits less spatial variability and has more uniform structure. Figure 7 when compared with Figures 5 and 6 relates the recharge spatial distribution with the correlation scale evolution for the rain series 1 . Different rain peaks, for the same realization of the conductivity field, result in similar magnitudes of the correlation scale. Similar behavior to that shown in Figure 7 was found for all realizations of the hydraulic conductivity field.

The spatial structure of the groundwater recharge, therefore, depends on the stage of the recharge process and can be described with a covariance function, or variogram: $C_{R}(\mathbf{r})=\sigma_{R}^{2}-\gamma(\mathbf{r})$. Figure 8 shows three experimental variograms cor- 


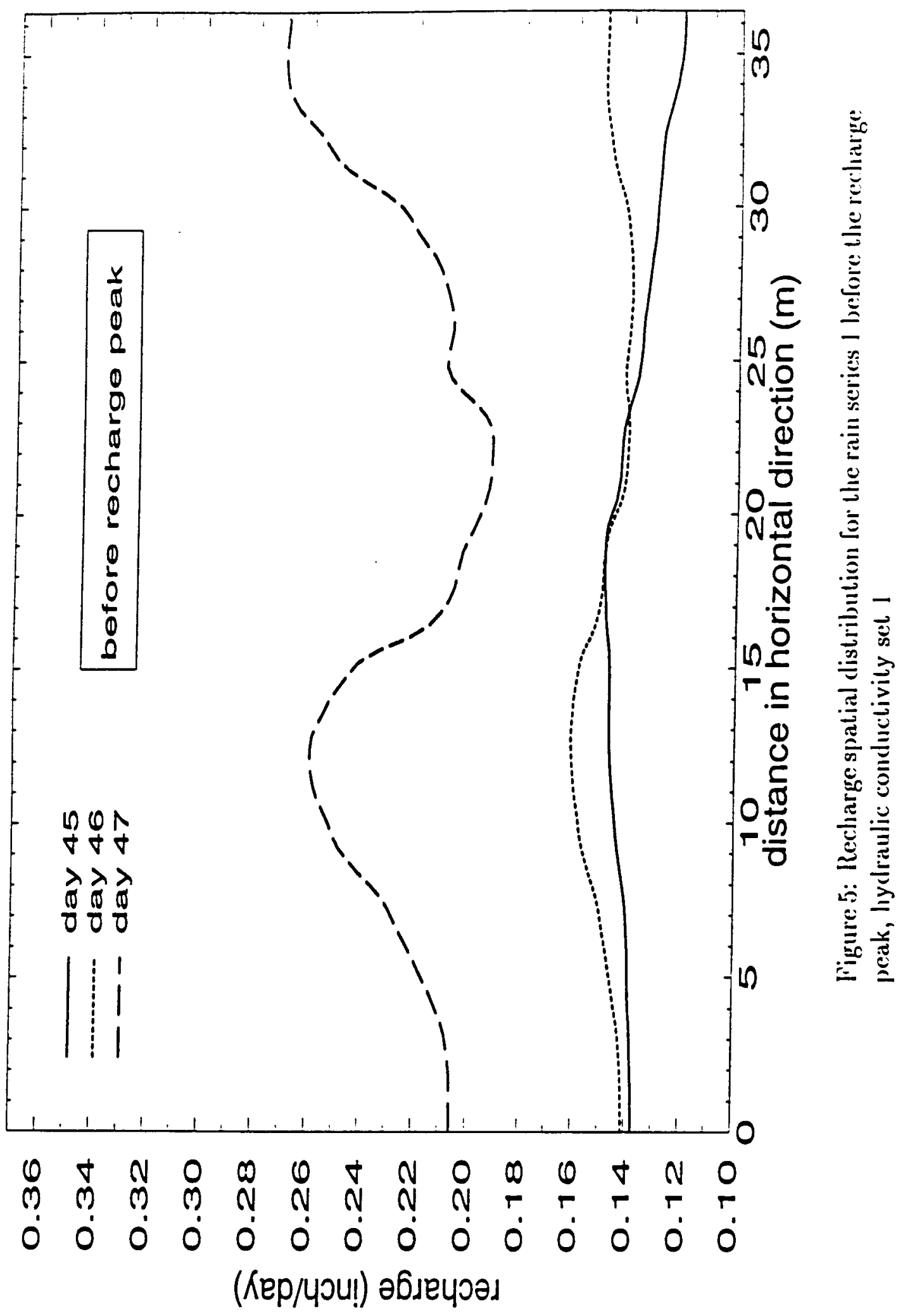




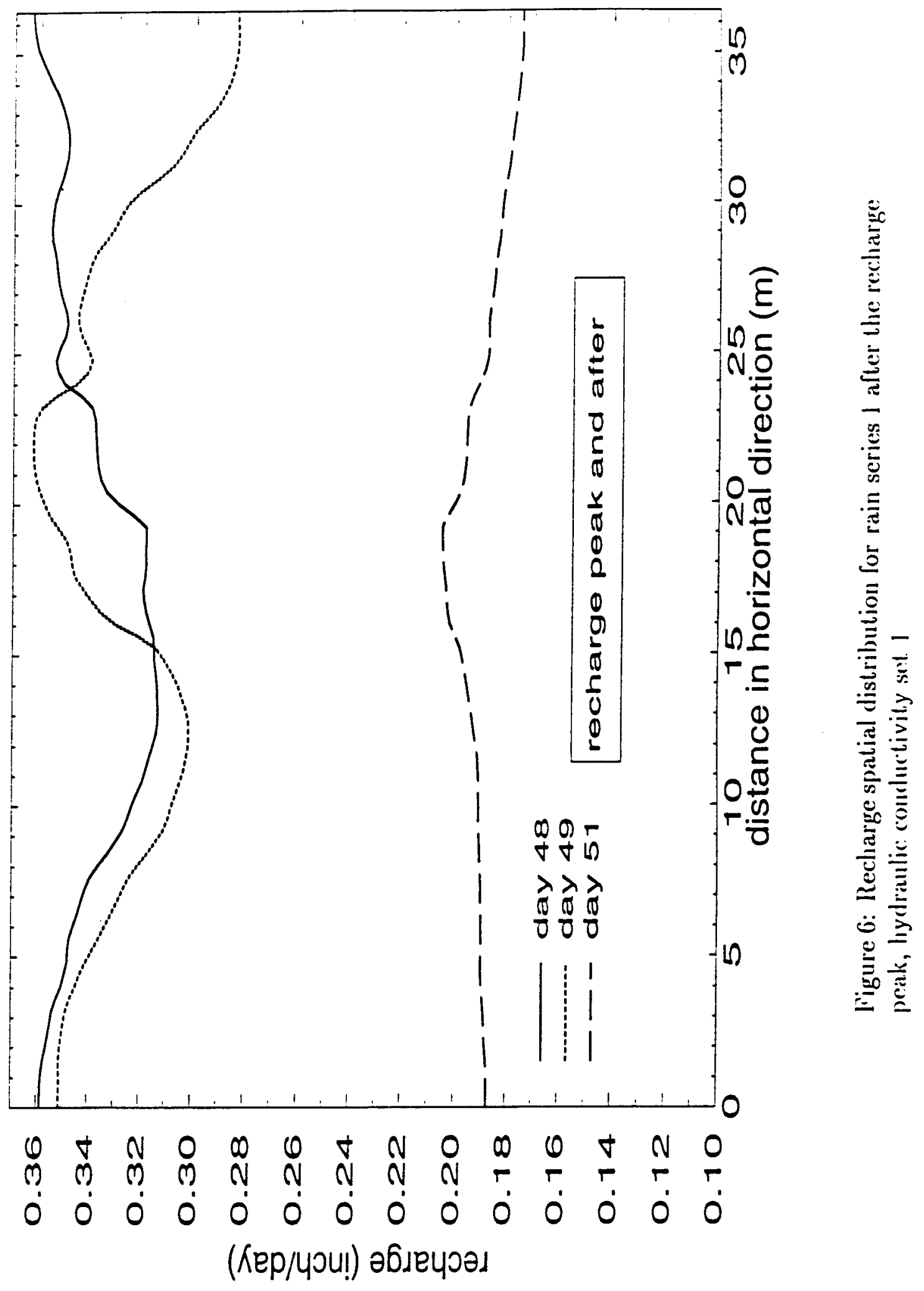




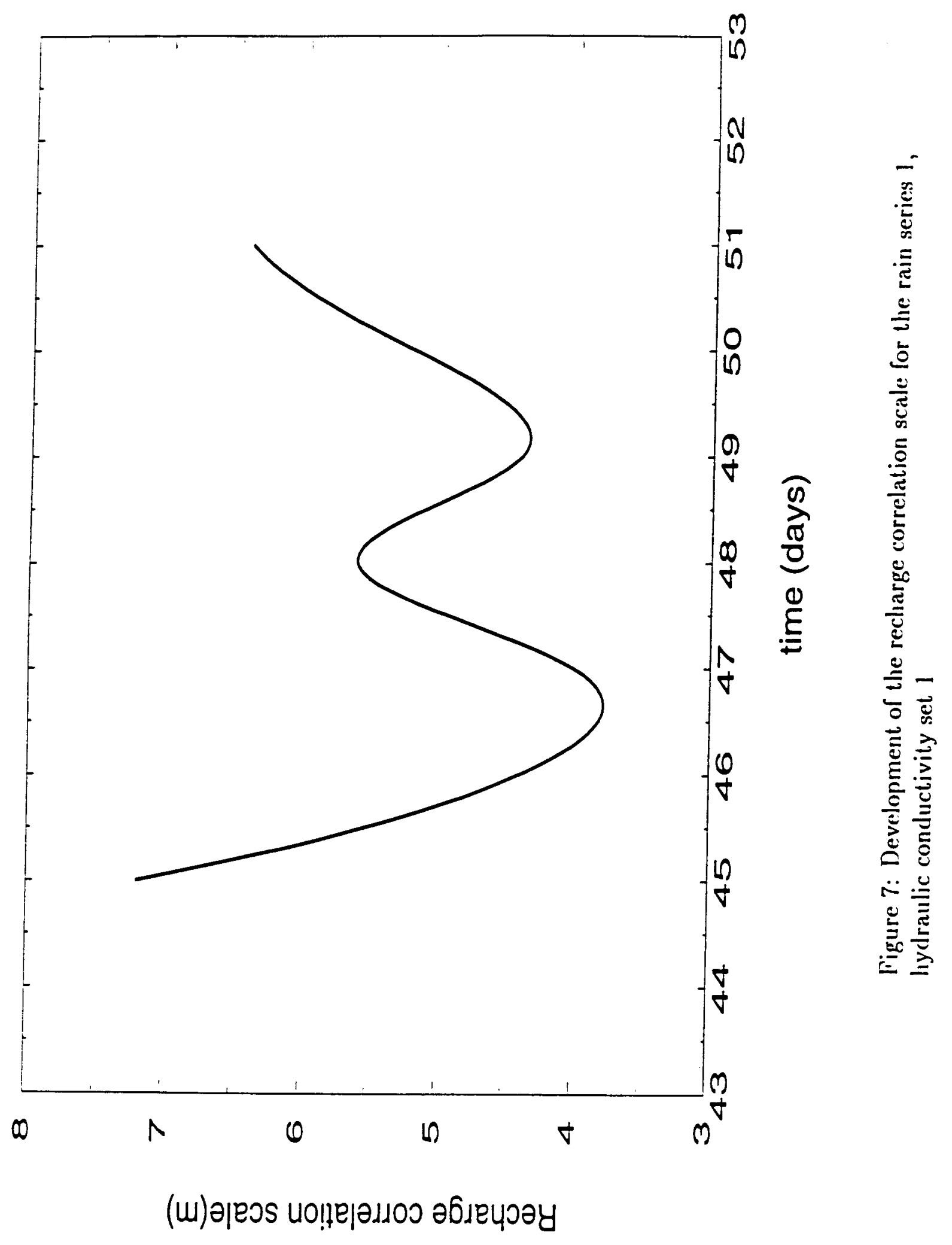




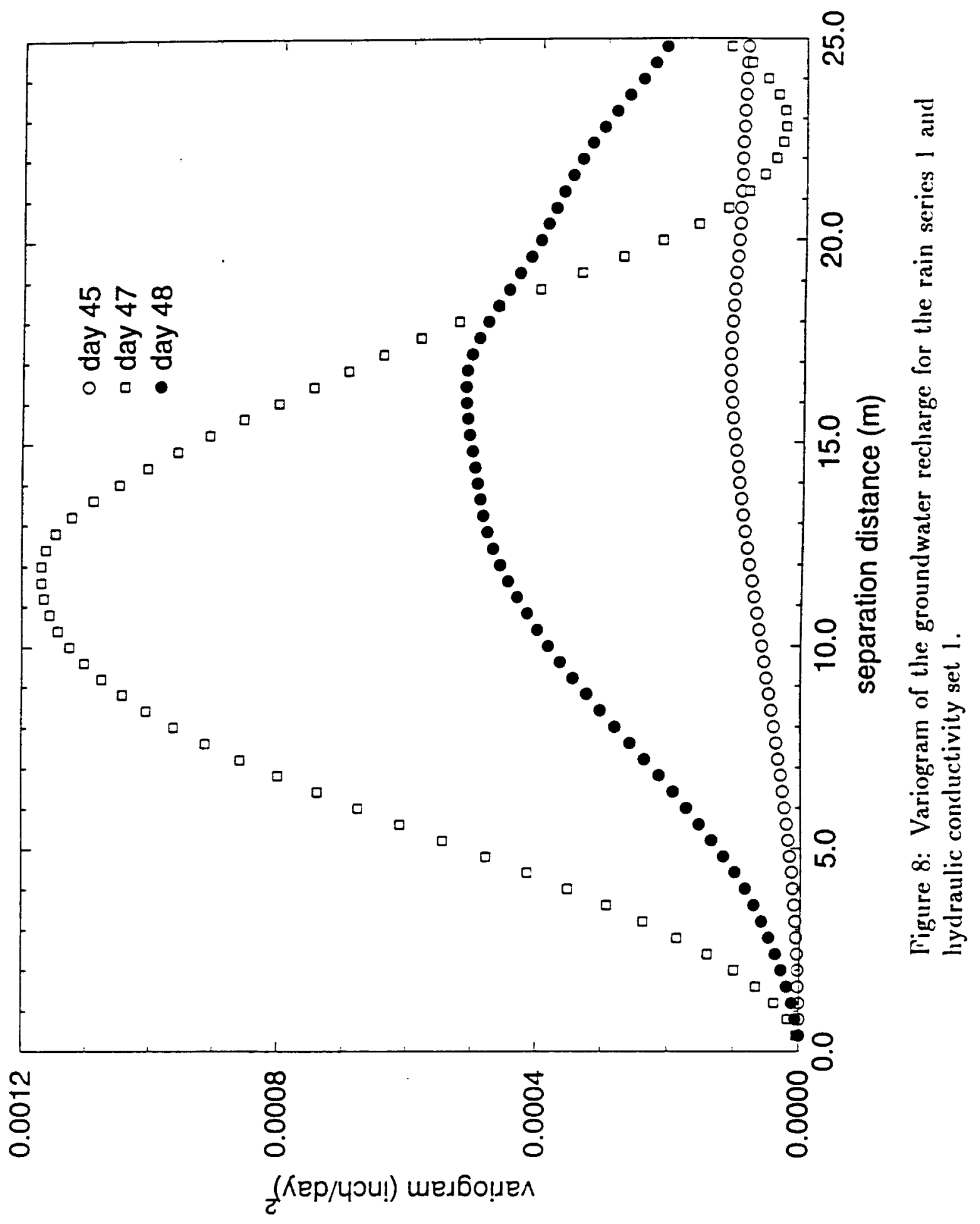


responding to different stages of the recharge process for the rain series 1 . During the recharge peak, the recharge variogram seems to indicate periodicity. This periodicity in space was caused mainly by the preferential flow patterns, and it was found in all hydraulic conductivity realizations, with only different magnitudes. It is difficult to quantify this periodicity using the results only from the numerical experiment, because the domain in the horizontal direction needs to be much larger.

The theoretical variogram, selected to fit the experimental variogram shown in Figure 8 is given as:

$$
\gamma(\mathbf{r})=s \cdot\left[1-\frac{\sin (\beta \mathbf{r})}{\beta \mathbf{r}}\right]
$$

where $s$ is the sill of the variogram and $\beta$ is a parameter related to the integral scale. The model parameters depend on the particular realization of the conductivity field and are determined using least square fitting. The variogram model (equation 12) has a periodic behavior for larger separation distances and continuity with parabolic behavior for small separation distances. The continuity for small separations is expected for the groundwater recharge and it reflects the recharge definition in equation (3). The flow in the saturated zone below the phreatic surface and the phreatic-surface elevation changes exhibit little variation for smaller separation distances.

Figure 9 shows that the selected variogram model (equation 12) with the estimated parameters fits well the experimental data obtained from the numerical experiment. The variogram model is found to be applicable at all time stages around the recharge peak, with different parameter values.

The covariance function model follows from the variogram model as:

$$
C_{R}(\mathbf{r})=s-\gamma(\mathbf{r})=s \cdot\left[\frac{\sin (\beta \mathbf{r})}{\beta \mathbf{r}}\right]
$$

The recharge integral scale for the modeled covariance function is calculated as:

$$
\lambda_{R}=\frac{1}{s} \int_{0}^{\infty} s \frac{\sin (\beta \mathbf{r})}{\beta \mathbf{r}} d \mathbf{r}=\frac{\pi}{2 \beta}
$$

For the case presented in Figure 9 which corresponds to day 47 of rain series 1 , the integral scale is equal to $4.9(\mathrm{~m})$ or approximately $4 \lambda_{x}\left(\lambda_{x}\right.$ being the horizontal correlation scale of the hydraulic conductivity field).

Examination of the evolution of the groundwater recharge integral scale within the 90-day interval clearly indicates that the groundwater recharge has significantly reduced correlation scale during the recharge peaks. During these periods the groundwater recharge exhibits strong spatial non-uniformity and results in highly variable flow conditions in the saturated zone, which is manifested through variable 


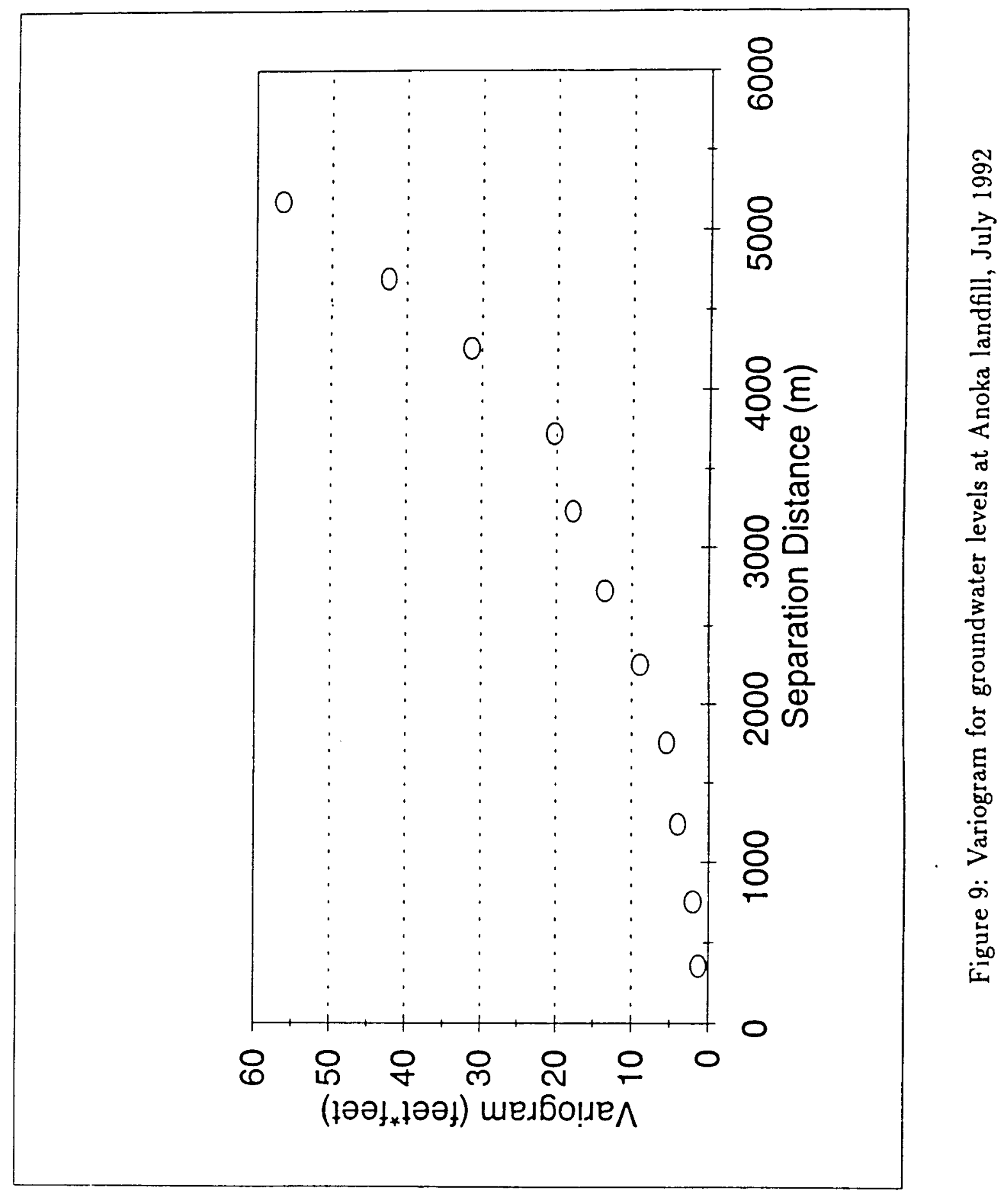


direction and flow magnitude. The integral scale (equation 14) was examined for the stage just before the recharge peak when recharge exhibits spatial non-uniformity. Depending on the realization of the hydraulic conductivity, the integral scale reduces to two to five horizontal integral scales of the hydraulic conductivity field for the shallow aquifer example used in the experiment (Figure 7 ).

The continuity and parabolic behavior of the hypothesized theoretical variogram also was observed on the empirical variogram of water elevations measured at the Anolia landfill, Minnesota. This field was selected to test the proposed recharge definition and selected model for the recharge spatial structure. The spatial structure has been analyzed for six set of measurements from 1991 and 1992. All six variograms exhibit continuity and parabolic behavior for smaller separations (e.g. Figure 10). The correlation length was not estimated from these variograms because the hydraulic head levels are correlated over scales larger than the landfill scale. 


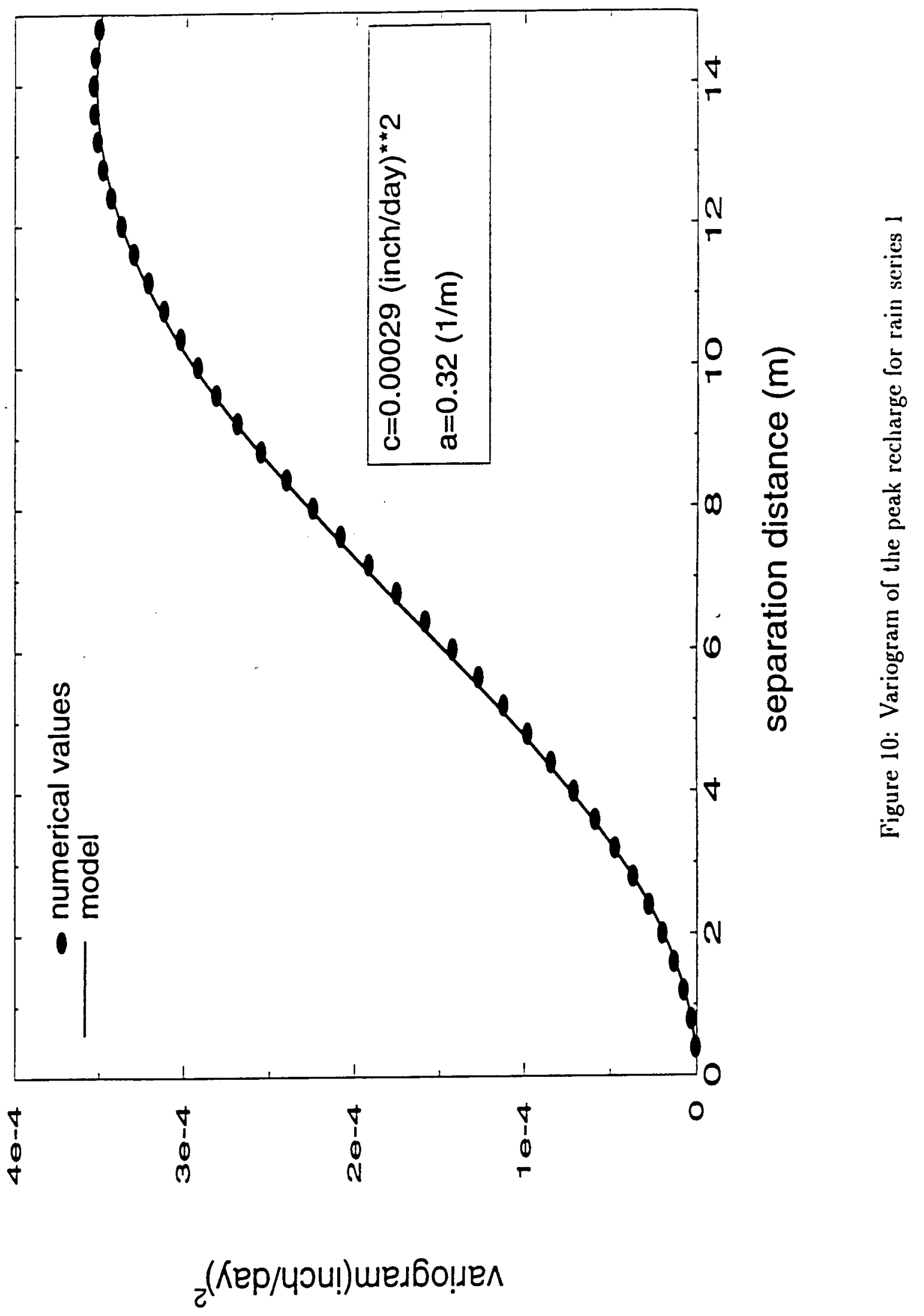




\section{Recharge Temporal Analysis}

Temporal distributions of spatially averaged recharge values are examined in this section. The recharge was averaged over the phreatic surface to form the recharge time series. Thirty different recharge time series (ten hydraulic conductivity realizations and three rain series) were obtained. Because the recharge series consists of spatially averaged recharge values, differences in realizations of the hydraulic conductivity do not significantly influence the groundwater recharge. As a result, only the mean recharge series, obtained as an average over ten hydraulic conductivity realizations, are used for the temporal analysis.

The recharge process was examined in the frequency domain using linear transferfunction methodology. Frequency domain models are often used in groundwater flow and quality modeling (Duffy and Gelhar, 1985; Duffy and Gelhar, 1986; Ritzi Jr. et al., 1991) under the assumption of stationarity of the input (rain) and output (recharge) processes. This results in presenting recharge, $R(t)$, through the convolution integral as:

$$
R(t)=\int_{-\infty}^{\infty} k(t-\tau) P(\tau) d \tau
$$

where $P(t)$ is the input process (precipitation intensity) and $k(t)$ is a kernel function (impulse-response) defined as the inverse Fourier transform of the transfer function $H(f)$ as:

$$
k(t)=\int_{-\infty}^{\infty} H(f) e^{2 \pi i f t} d f
$$

with the transfer function magnitude $|H(f)|^{2}=S_{R}(f) / S_{P}(f)$ where $S_{R}(f)$ and $S_{P}(f)$ are the recharge and precipitation power spectral densities, respectively. The numerical results show that the rain spectrum is more or less constant over all frequencies (indicating its random structure) while the recharge spectrum has a decreasing trend indicating its non-zero temporal correlation.

Under the assumption of linearity (or quasi-linearity) it is expected that the kernel function obtained from equation (16) will be able to predict the system output for a particular rain event. If in addition the same kernel function can predict the system output for other rain events, the system can be treated as unique within a given season. It is the intention of this numerical analysis to examine the assumption of linearity and to identify possible causes of nonlinearity. To properly address this issue an extensive set of recharge measurements would be needed. Such measurements are, however, seldom available, and our study therefore used numerical simulation to obtain recharge values.

Based on the numerically obtained kernel functions the following relation is proposed as a possible kernel-function model:

$$
k(t)=a t^{2} e^{-b t}
$$


where $a$ and $b$ are parameters related to the time lag between the rain and recharge and to the kernel function maximum value. The parabolic behavior at the origin results in the delay between rain and recharge events, while the exponential tail simulates the recharge behavior when the rain event is over. Jankovic (1993) demonstrated the relationship between the parameters in equation (17) and physical characteristics of the system and derived the estimates of the kernel function parameters in the form:

$$
b=\frac{2}{t_{\max }} \quad a=\frac{7.4 k_{\max }}{t_{\max }^{2}}
$$

where $t_{\max }$ is a time lag between the input and the peak of the kernel function and $k_{\max }$ is the value of the kernel function at time $t_{\max }$. The time lag $t_{\max }$ depends on the heterogeneity of the hydraulic conductivity field and the distance from the soil surface to the phreatic surface. It represents the arrival time of the largest influence on the recharge process. On the other hand, the magnitude of $k_{\max }$ depends on the evapotranspiration intensity and the soil moisture distribution. This can be easily seen by assuming rain of unit intensity, constant in time, such that the recharge equals the integral of the kernel function. The parameter $k_{\max }$ then is proportional to $t_{\max }^{-1} \int k(t) d t$. The integral of the kernel function determines the attenuation of the recharge magnitude that is caused by the evapotranspiration and soil moisture redistribution resulting from the rain event. Its value equals the ratio between the effective rain and the total rain.

The parameters of the kernel function (equation 17) can be measured through tracer experiments or calculated from numerical experiments simulating the transformation of a single rain event into recharge. Once the model parameters are estimated, the model can be used to transform the rain event into the recharge within the same season. This seasonal approach was used by Morel-Seytoux (1984) for transformation of the effective rainfall into recharge.

Figure 11 shows the numerically obtained kernel function for the first rain series and the kernel function model with parameters $a=0.13\left(1 / d_{a y}{ }^{3}\right)$ and $b=$ $0.57(1 /$ day $)$, calculated using estimates $t_{\max }=3.5($ day $)$ and $k_{\max }=0.22(1 /$ day $)$ obtained from the numerically calculated kernel function. The transfer function magnitude obtained analytically from equation (16) is in good agreement with the numerically obtained transfer function magnitude (Janković, 1993).

Recharge modeled using the convolution integral in equation (15) is based on the assumption of the system linearity. However, due to system heterogeneity and the evapotranspiration process, the recharge may depart from the linearity assumption. One way of comparing and identifying the causes of possible nonlinearity is by comparing the results of the numerical experiment with the convolution integral in equation (15). Figure 12 shows that comparison for three rain series of the same season (June - August). Recharge from the convolution has the same parameters $a$ 


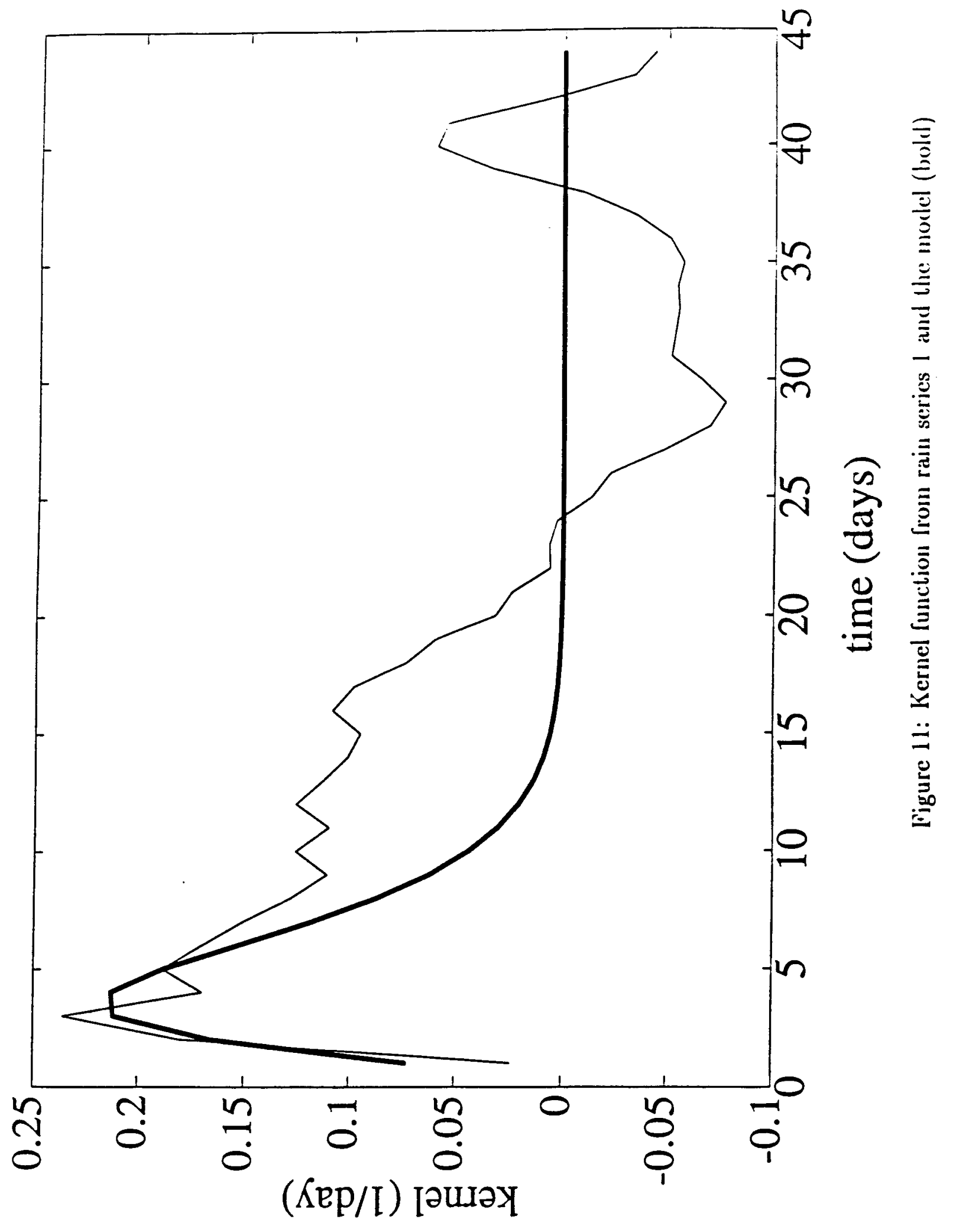



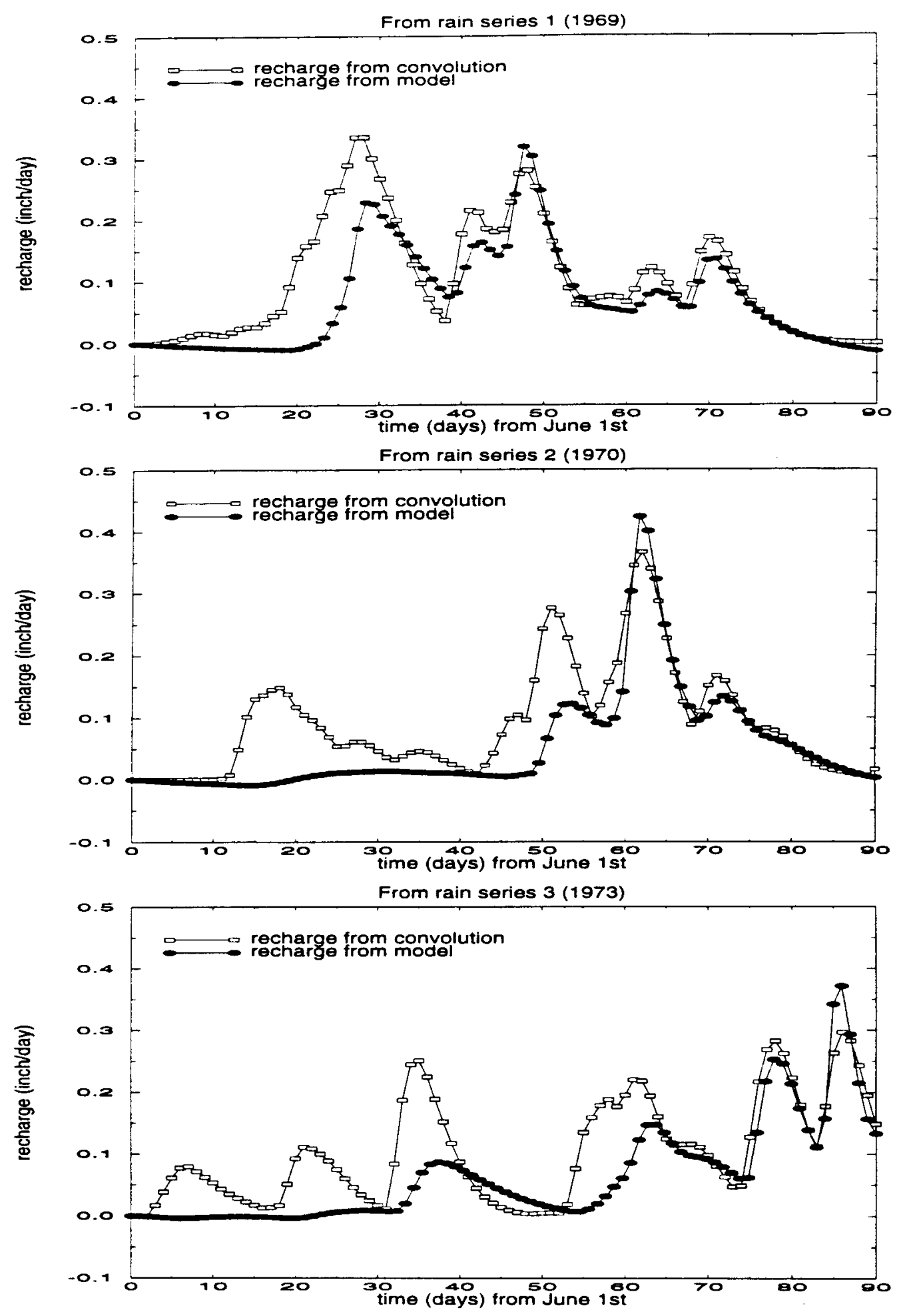

Figure 12: Comparison of the average recharge series (obtained using a numerical model) and the series obtained by convolution 


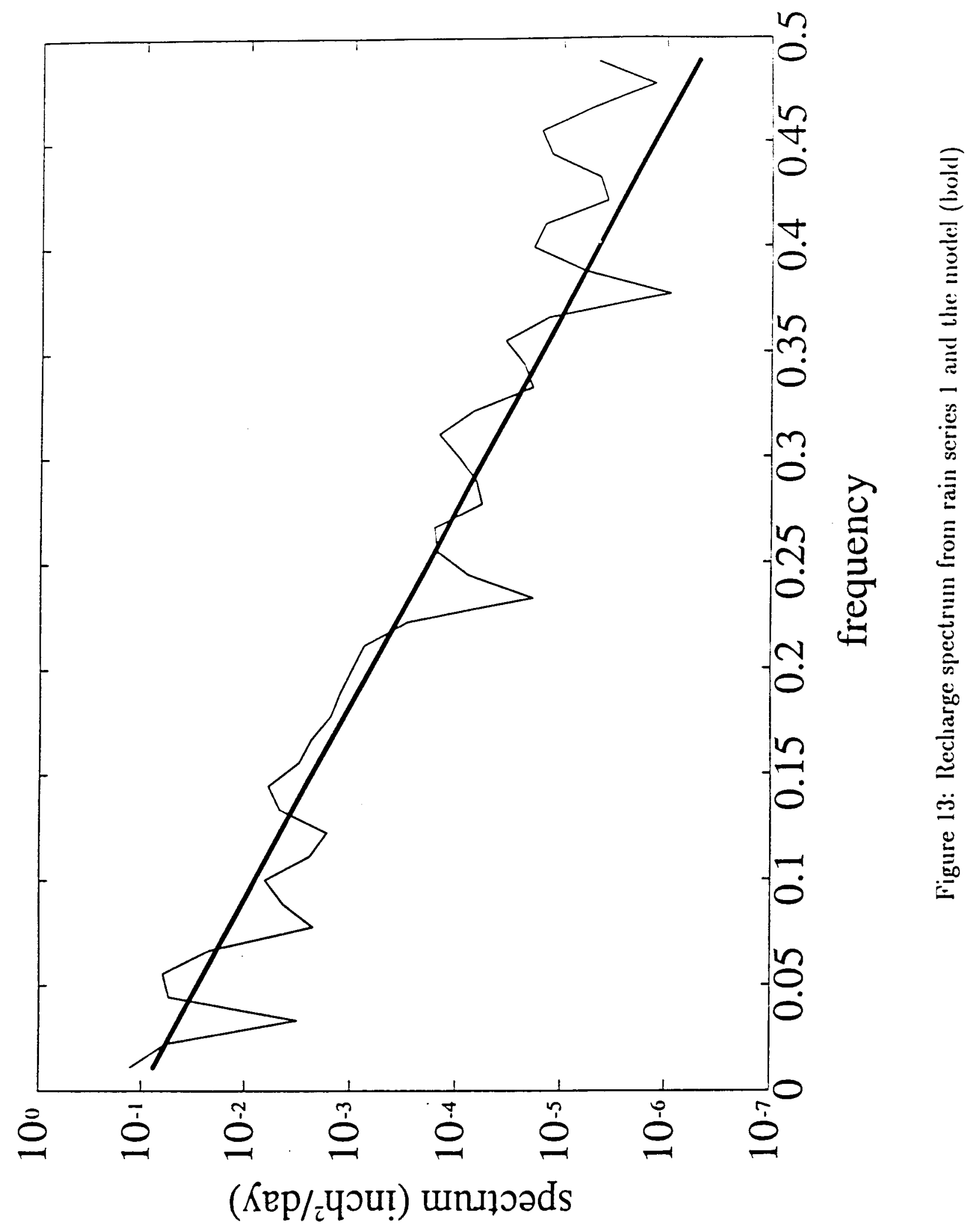


the 2-D case. The value of the effective hydraulic conductivity of $2.2 \cdot 10^{-5} \mathrm{~m} / \mathrm{s}$ was found to have the "best" match with the 2-D model and is presented in Figure 14. Clearly this value of effective hydraulic conductivity represents the trade-off between matching the recharge peak magnitude and its arrival time. It seems that the lateral flow and the redistribution of saturation during the infiltration process result in the smoothing effect on the recharge peak magnitude and influences its arrival time at the phreatic surface. These results are in agreement with the results reported by Protopapas and Bras (1991).

One-D models with an effective hydraulic conductivity are capable of balancing out recharge peak magnitude and its arrival time. The best-fit effective hydraulic conductivity seems to be somewhere between the geometric and harmonic mean values. The actual value will depend on the degree of stratification and the depth to the phreatic surface. In the case of very shallow aquifers, where there is no strong lateral flow, a 1-D model with estimated effective parameters might have acceptable accuracy in predicting groundwater recharge. 


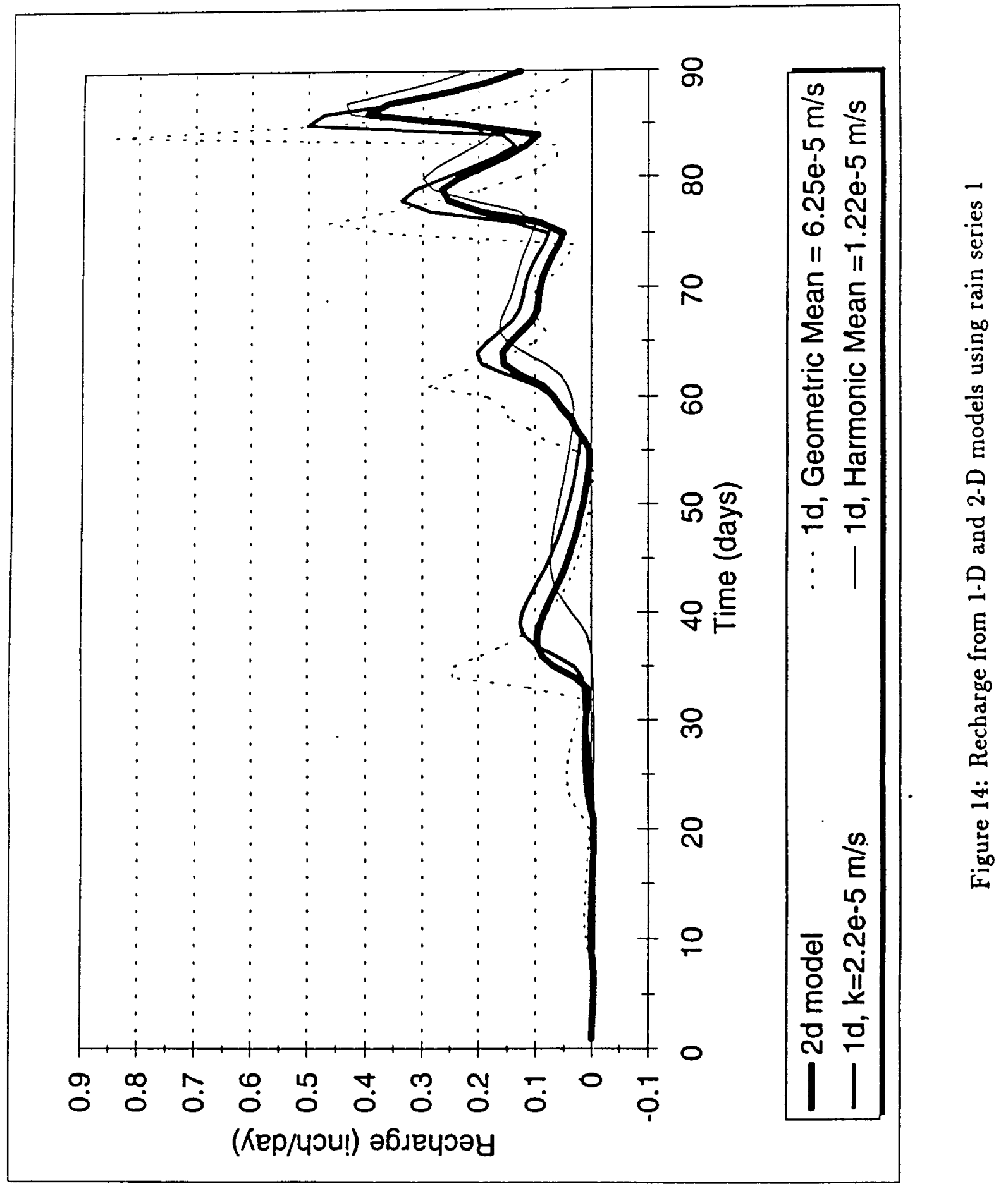




\section{Spatial and Temporal Sampling Design for Un- steady Groundwater Flow}

Monitoring of spatially and temporally distributed hydrologic variables is essential for characterization of the subsurface environment. A problem of special practical importance is that of cost-effective monitoring of groundwater flow fluctuations by means of an optimally selected space-time sampling network. It is possible to evaluate a trade-off between the spatial network design and sampling frequency (Andričević, 1990) such that the acceptable accuracy is maintained. The most important input in the spatial and temporal sampling design for the groundwater flow comes from the recharge temporal structure. In this study, we followed the sampling design methodology introduced in the work of Andričević and FoufoulaGeorgiou (1991). The basic sampling criterion follows classical results in spectral theory (e.g., Blackman and Tukey, 1959), with the mean square error evaluated in the form

$$
\sigma_{\epsilon}^{2}=\int_{-\infty}^{+\infty}|H(k, \omega)|^{2} S_{h}(k, \omega) d k d \omega
$$

where $S_{h}(k, \omega)$ is the spectral density function of the hydraulic head $h(\mathbf{x}, t), k$ is the wave number, $\omega$ is the frequency, and $|H(k, \omega)|^{2}$ is a sampling error filter which explicitly relates to sampling network design via its dependence on spatial spacing between the wells $\Delta l$ and temporal sampling frequency $\Delta t$ (for more details see Andričević and Foufoula-Georgiou, 1991). The hydraulic head spectrum can be derived following the spectral approach applied on the unsteady two-dimensional groundwater flow equation

$$
\frac{\partial^{2} h}{\partial x_{i} \partial x_{j}}+\frac{\partial Y}{\partial x_{i}} \frac{\partial h}{\partial x_{i}}=\exp (-Y)\left[S_{y} \frac{\partial h}{\partial t}-R\right]
$$

where $R$ is the groundwater recharge temporally variable and locally constant in space, $S_{y}$ is the specific storage coefficient and $Y=\ln T$ is the log-hydraulic conductivity field. Introducing a small perturbation in the hydraulic head in space and recharge in time, the mean removed equation can be written using the FourierStieltjes representation for the perturbed quantities as

$$
-k^{2} d Z_{h^{\prime}}-i k_{i} J_{i} d Z_{T^{\prime}}=\frac{1}{T_{g}}\left[i \omega S_{y} d Z_{h}+\bar{R} d Z_{T^{\prime}}-d Z_{R^{\prime}}\right]
$$

where $J_{i}=-\partial \bar{H} / \partial x_{i}$ is the gradient of the slowly varying ensemble mean hydraulic head, $k^{2}=k_{1}^{2}+k_{2}^{2}$, and $d Z_{h^{\prime}}, d Z_{T^{\prime}}$, and $d Z_{R^{\prime}}$ are complex random amplitudes for the perturbations in the hydraulic head, transmissivity, and recharge, respectively. Multiplying by the conjugate and taking the expected value in equation (23), the spectrum of the unsteady hydraulic head field is obtained from 
$E\left[d Z_{h^{\prime}} d Z_{h^{\prime}}^{\star}\right]=S_{h}(k, \omega) d k d \omega$. Since the input spectrum of the transmissivity is time-invariant and the recharge spectrum is assumed spatially constant within the monitoring domain, we may write:

$$
S_{T}(k, \omega)=S_{T}(k) \delta(\omega) \quad S_{R_{t}}(k, \omega)=S_{R_{t}}(\omega) \delta(k)
$$

where $\delta()$ is the Dirac delta function. Using the above two spectra, the hydraulic head spectrum is evaluated and substituted in equation (21) to yield the sampling error variance for the unsteady groundwater flow as

$$
\sigma_{\epsilon}^{2}=\int_{k=-\infty}^{\infty}|H(k, 0)|^{2} \frac{\left(\frac{\bar{R}}{T_{g}}\right)^{2}+\left(k_{i} J_{i}\right)^{2}}{k^{4}} S_{T}(k) d k+\int_{\omega=-\infty}^{\infty}|H(0, \omega)|^{2} \frac{S_{R_{t}}(\omega)}{\left(S_{y} \omega\right)^{2}} d \omega
$$

where $|H(k, 0)|^{2}$ and $|H(0, \omega)|^{2}$ are sampling error filters for the spatial and temporal network designs, respectively. Using the approximation in the sampling error filter in the form of the Dirac comb (see Andričevic and Foufoula-Georgiou, 1991), the sampling error variance further simplifies to:

$$
\sigma_{\epsilon}^{2} \cong \frac{4}{L_{1} L_{2}} \sum_{n_{1}=1, n_{2}=1}^{\infty} \frac{\left(\frac{\bar{R}}{T_{g}}\right)^{2}+\left(k_{i} J_{i}\right)^{2}}{k^{4}} S_{T}\left(\frac{2 \pi n_{1}}{\Delta l_{1}}, \frac{2 \pi n_{2}}{\Delta l_{2}}\right)+\frac{2}{T} \sum_{n_{3}}^{\infty} \frac{S_{R}\left(\frac{2 \pi n_{3}}{\Delta t}\right)}{S_{y}^{2}\left(\frac{2 \pi n_{3}}{\Delta t}\right)}
$$

This sampling error variance formula can be evaluated easily when the transmissivity spectrum and the recharge spectrum are given. The sampling network design parameters are, the spatial spacing between the wells $\left(\Delta l_{i}\right)$ and the temporal sampling frequency $(\Delta t)$. The monitoring spatio-temporal domain is given by $L_{1} \times L_{2} \times T=N_{1} \Delta l_{1} \times N_{2} \Delta l_{2} \times N_{3} \Delta t$. The sampling error from the temporal variability of the recharge process is additive to the sampling error resulting from the soil heterogeneity. Due to the relatively slow fluctuations in the hydraulic head, the recharge temporal variability will have a major impact on sampling design, and frequent sampling can be more cost-effective than dense spatial sampling. Figure 15 shows the sampling performance measured by the sampling error in equation (26) for the case of isotropic transmissivity field (with an exponential covariance function) and temporal recharge variability as obtained for rain series 1 .

Two spatial spacings are shown on Figure 15, one with $\Delta l=10 \mathrm{~m}$ and the other with $\Delta l=50 \mathrm{~m}$. It is clear that at small sampling frequencies the spatial spacing makes a difference in the sampling performance. However, when the sampling frequency is increased, the error resulting from the recharge temporal variability overtakes the total sampling error and at some point the recharge temporal variability error constitutes the entire sampling error. This joint influence of the spatial and temporal variability of the recharge process is very important in decision making, and only its trade-off will provide the basis for a cost-effective sampling network design for groundwater quality and quantity monitoring. 


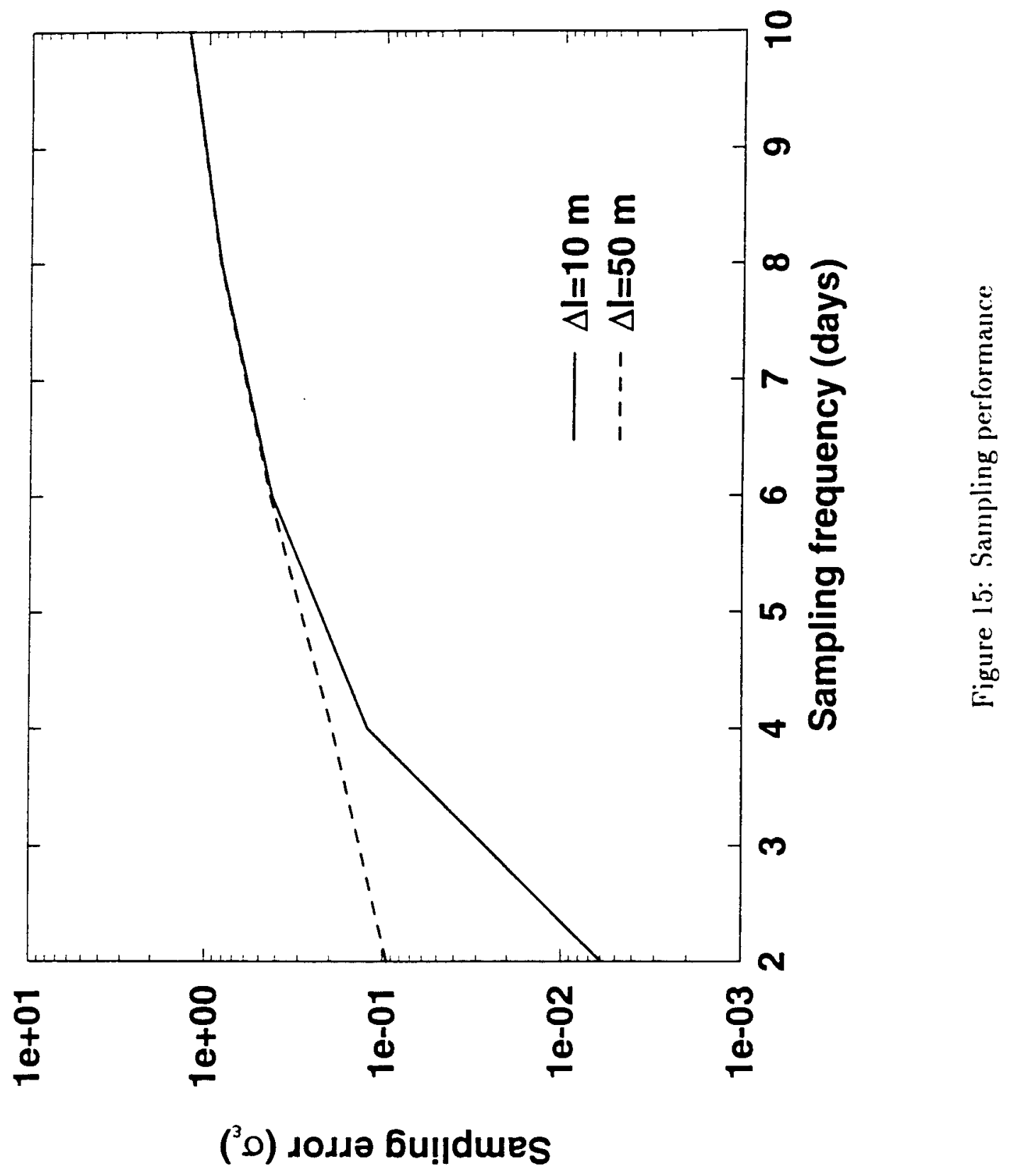


case for shallow aquifers and frequent rain events of similar intensity within a given season. However, in all other cases the upper soil zone, which exhibits strong lateral flow and redistribution of saturation, usually brings a strong non-linear effect in the transition process from rain into recharge. The temporal variability of the recharge also has a strong impact on the sampling error. Only through the trade-off between the spatial and temporal sampling design can the most cost-effective monitoring network be designed. 


\section{References}

Andričević, R., Cost-effective network design for groundwater flow monitoring, Stochastic Hydrol. Hydraul., 4(1), 27-41, 1990.

Andričević, R. and E. Foufoula-Georgiou, A transfer function approach to sampling network design for groundwater contamination, Water Resour. Res., 27, 2759-2769, 1991.

Allison, G. B., A Review of Some of the Physical, Chemical and Isotopic Techniques Available for Estimating Groundwater Recharge, Estimation of natural groundwater recharge, edited by I. Simmers, Kluwer Academic Publishers, Dordrecht, the Netherlands, 1988.

Anderson, M. P. and W. W. Woessner, Applied Groundwater Modeling: Simulation of Flow and Advective Transport, 381 pp., Academic Press, Inc., San Diego, Cal., 1992.

Bear, J., Introduction to Modeling of Transport Phenomena in Porous Media, 553 pp., Kluwer Academic Publishers, Dordrecht, The Netherlands, 1991.

Besbes, M. and G. de Marsily, From infiltration to recharge: Use of a parametric transfer function, J. Hydrol., 74, 271-293, 1984.

Blackman, R. B. and J. W. Tukey, The Measurement of Power Spectra, Dover, New York, 1959.

Duffy, C. J. and L. W. Gelhar, A frequency domain approach to water quality modeling in groundwater: Theory, Water Resour. Res., 21, 1175-1184, 1985.

Duffy, C. J. and L. W. Gelhar, A Frequency Domain Analysis of Groundwater Quality Fluctuations: Interpretation of Field Data, Water Resour. Res., 22, 1115-1128, 1986.

van Genuchten, M. Th., A Closed-form equation for predicting the hydraulic conductivity of unsaturated soils, Soil Sci. Soc. Am. J., 44, 892-898, 1980.

Gröbner, W. and N. Hofreiter, Bestimmte Integrale, 204 pp., Springer-Verlag, Vienna, Austria, 1966.

Hills, R. G., P. J. Wierenga, D. B. Hudson and M. R. Kirkland, The second Las 
Cruces trench experiment: Experimental results and two-dimensional flow predictions, Water Resour. Res., 27, 2707-2718, 1991.

Janković, I., Numerical simulation of groundwater recharge: Spatial and temporal analysis, M.S. thesis, 122 pp., Univ. of Minn., Minneapolis, Minn., 1993.

Johnston, C. D., Preferred water flow and localised recharge in a variable regolith, J. Hydrol., 94, 129-142, 1987.

Jury, W. A., Simulation of solute transport using a transfer function model, Water Resour. Res., 18, 363-368, 1982.

Jury, W. A., G. Sposito and R. E. White, A transfer function model of solute transport hrough soil, 1. Fundamental concepts, Water Resour. Res., 22, 243-247, 1986.

Kirkland, M. R., R. G. Hills and P. J. Wierenga, Algorithms for solving Richards' equation for variably saturated soils, Water Resour. Res., 28, 2049-2058, 1992.

Lachassagne, P., E. Ledoux and G. de Marsily, Evaluation of Hydrogeological Parameters in Heterogeneous Porous Media, Groundwater management: Quantity and quality, edited by A. Sahuquillo, J. Andreu and T. O'Donnell, IAHS publication No. 188, Madrid, Spain, 1989.

Morel-Seytoux, H, J., From excess infiltration to aquifer recharge: A derivation based on the theory of flow of water in unsaturated soils, Water Resour. Res., 20, 1230-1240, 1984.

Polmann, D. J., D. McLaughlin, S. Luis, L. W. Gelhar and R. Ababou, Stochastic modeling of large-scale flow in heterogeneous unsaturated soils, Water Resour. Res., $27,1447-1458,1991$.

Protopapas, A. L. and R. L. Bras, The one-dimensional approximation for infiltration in heterogeneous soils, Water Resour. Res., 27, 1019-1027, 1991.

Quinn, J. J., H. D. Mooers and H-O. Pfannkuch, An approach to groundwater monitoring well network design relying on numerical techniques and public-domain information, 44 pp., Tech. Rep. No. 138, Minnesota Water Resources Research Center, St. Paul, MN, 1994.

Ritzi Jr., R. W., S. Sorooshian and V. K. Gupta, On the estimation of parameters for frequency domain models, Water Resour. Res., 21, 873-882, 1991. 
Rubin, Y. and G. Dagan, Stochastic identification of transmissivity and effective recharge in steady groundwater flow, 1, Theory, Water Resour. Res., 23, 1185-1192, 1987.

Sharma, M. L. and M. W. Hughes, Groundwater recharge estimation using chloride, deuterium and oxygen-18 profiles in the deep coastal sands of western Australia, $J$. of Hydrol., 81, 93-109, 1985.

Solomon, D. K. and E. A. Sudicky, Tritium and helium 3 isotope ratios for direct estimation of spatial variation in groundwater recharge, Water Resour. Res., 27, 2309-2321, 1991.

Srebrenovic, D., Primijenjena Hidrologija, Skolska Knjiga, Zagreb, Croatia, 1986.

Tompson, A. F. B., R. Ababou and L. W. Gelhar, Applications and Use of the Three-dimensional Turning Bands Random Field Generator: Single Realization Problems, 126 pp., Massachusetts Institute of Technology, Boston, Mass., 1987.

Topp, G. C., J. L. Davis and A. P. Annan, Electromagnetic determination of soil water content: measurements in coaxial transmission lines, Water Resour. Res., 16, $574-582,1980$.

White, R. E., J. S. Dyson, R. A. Haigh, W. A. Jury and G. Sposito, A transfer function model of solute transport through soil, 2. Illustrative applications, Water Resour. Res., 22, 248-254, 1986. 